\title{
O DIRETOR DE ESCOLA PÚBLICA MUNICIPAL FRENTE ÀS ATRIBUIÇÕES DA GESTÃO ADMINISTRATIVA
}

http://dx.doi.org/10.5902/2318133830020

\author{
Ione Oliveira Jatobá Leal \\ Universidade do Estado da Bahia, Brasil. \\ Ivan Luiz Novaes \\ Universidade do Estado da Bahia, Brasil.
}

\begin{abstract}
Resumo
Este artigo decorre de uma pesquisa sobre a percepção dos diretores acerca da gestão em escolas municipais de Jacobina/Bahia. Teve como objetivo analisar como os diretores percebem as atribuições da gestão administrativa que lhes são demandadas para desenvolver a gestão. Utilizamos como instrumento de coleta de dados um questionário e como método um estudo de caso, que faz uso de variáveis predominantemente ordinais, decorrentes da aplicação de escala tipo Likert. Concluímos que a maioria dos diretores está sobrecarregado com ações administrativas, o que impacta negativamente sobre outras atividades da gestão.
\end{abstract}

Palavras-chave: gestão em escola pública; atribuições do diretor; gestão administrativa.

\section{THE PRINCIPAL OF PUBLIC SCHOOLS TO THE ADMINISTRATIVE MANAGEMENT ATTRIBUTIONS}

\section{Abstract}

This work is based on a research about the principals' perception about the management of municipal schools in Jacobina/Bahia. It aimed to analyze how principals perceive the administrative management attributions that are required of them to develop the management. We used as a data collection instrument questionnaire and adopted as a method a case study that makes use of predominant ordinal variables, resulting from the application of Likert scale. We concluded that most principals are overwhelmed with this type of activity, impacting negatively on other management activities.

Key-words: management in public school; attributions of the principal; administrative management. 


\section{Introdução}

A escola pública municipal tem passado por mudanças significativas no seu formato de gestão. Tais mudanças trouxeram novas demandas que refletiram no cotidiano da escola e impactaram na ação do diretor. As mudanças que afetam as ações do diretor dizem respeito principalmente ao envolvimento da comunidade interna e externa nas decisões da escola. Isso imprime um olhar diferenciado no tocante à forma de gerir a unidade escolar. Essas mudanças decorrem das políticas públicas que formam um amplo arcabouço legal.

Essas políticas ensejaram a possibilidade para os municípios criarem e implantarem seus sistemas de ensino, como também trouxeram orientações sobre novas formas de gestão a serem adotada nas escolas públicas. No que se refere às orientações para a gestão nas unidades escolares, a LDB/96, no art. 12, incisos I a VII, apresenta as diretrizes de gestão que orientam as ações a serem desenvolvidas nas escolas, levandose em conta as normas comuns e as do seu sistema de ensino.

O poder na escola estava centrado nas mãos de poucos e as decisões eram tomadas numa relação vertical e de subordinação, seja no âmbito da execução das políticas educacionais entre os entes que compõe a federação União, Estados e Municípios, ou mesmo no interior dos sistemas educativos, no caso as secretarias de educação estaduais ou municipais, as suas congêneres regionais ou as escolas (Nascimento; Leal; Novaes, 2014).

Algumas atividades, até a década de 1980, não eram de responsabilidade do diretor, a exemplo de gerir recursos financeiros, preocupação direta com a parte pedagógica e inserir a comunidade escolar nas decisões da escola. Essas mudanças resultaram numa nova forma de agir do diretor, por exigir conhecimento dos processos de gestão da escola, das legislações educacionais, capacidade de negociação de conflitos e garantia da participação do poder público, do coletivo escolar e da comunidade local visando à melhoria do processo educativo. Ao exercer um cargo de direção cabe ao diretor conhecer melhor as bases do exercício efetivo de suas tarefas, visando desenvolver competências e habilidades para liderar de forma consciente as atribuições nas dimensões da gestão escolar.

Nesse contexto, gerir a escola "é organizar, mobilizar e articular todas as condições materiais e humanas necessárias para garantir o avanço dos processos socioeducativos das escolas" (Martins; Bocanelli, 2010, p. 81).

Neste caso, o diretor, sendo o principal responsável pela escola, possui atribuições que Ihes são demandadas para efetivação das ações. Para Libâneo, Oliveira e Toschi (2012), a direção é a responsável pela concretização do processo de tomada de decisão na organização e coordena os trabalhos, de modo que sejam executados da melhor maneira possível. Há de se destacar a importância do diretor da escola na articulação e envolvimento da comunidade escolar nas questões da escola.

As mudanças, novas atribuições e competências que estão sendo atribuídas aos diretores, poderão se contrapor com as funções ditas tradicionais na forma de gerir a escola. O cargo de direção tem uma posição fundamental e exerce fortes influências sobre todos os setores da escola, considerando o seu papel de liderança na condução dos aspectos administrativos e pedagógicos. 


\section{As atribuições do diretor na dimensão administrativa}

De acordo com Libâneo, Oliveira e Toschi (2012), as atribuições do diretor correspondem a todas as atividades de coordenação e acompanhamento das ações de pessoas, a realização do trabalho em equipe, a manutenção do clima de trabalho e avaliação do desempenho. Dessa forma, o diretor, ao assumir o cargo, é o principal responsável por fazer a escola funcionar mediante o trabalho de outras pessoas. Nessa perspectiva, é essencial que ele reconheça que sua função tem uma característica genuinamente interativa, isto é, está a serviço das pessoas e da organização. Portanto, as atribuições do diretor "devem traduzir os esforços necessário à implementação dos objetivos, metas, estratégias e métodos de ação previstos ou pressupostos ao desenvolvimento da escola" (Souza, 2010, p. 2).

A dimensão administrativa responde pelos "meios de trabalho que asseguram o atendimento dos objetivos e funções da escola" (Libâneo; Oliveira; Toschi, 2012, p. 465). Os referidos autores consideram as ações técnico-administrativas como atividades meio por considerar que são os serviços burocráticos. As atribuições técnico-administrativas realizadas pelo diretor na escola pública dizem respeito ao conhecimento das normas para funcionamento da escola, planejamento, organização e controle dos recursos financeiros, materiais, infraestrutura, supervisão e orientação de todas as pessoas a quem delega responsabilidades na escola, mediar conflitos, tomar decisão.

De modo complementar, estão relacionadas à execução e acompanhamento dos projetos e programas, da escola com a comunidade, integração com outras escolas e com os órgãos superiores: "São atividades que apesar de estarem relacionadas ao processo ensino-aprendizagem, não o fazem de maneira direta, elas poderão viabilizar ou serem pré-condições para realização direta do processo pedagógico que acontece em sala de aula" (Libâneo; Oliveira; Toschi, 2012, p. 496).

Luck (2013) identificou um conjunto de atribuições concernentes aos diretores de escola, quais sejam: a) organizar e articular as unidades competentes da escola; b) controlar os aspectos materiais e financeiros; c) articular e controlar os recursos humanos; d) articular escola-comunidade; e) articular com os organismos superiores do sistema educacional; f) formular normas, regulamentos e adotar medidas levando em conta os objetivos e princípios propostos; g) supervisionar e orientar as pessoas a quem são atribuídas responsabilidades.

Numa linha muito próxima de entendimento sobre as atribuições do diretor no que se tange à dimensão administrativa, para Souza (2010)

a gestão da burocracia, dos recursos, do espaço físico, de pessoal; a implementação de programas e ações suscitados ou fomentados pela política educacional; a articulação com as esferas administrativas do respectivo sistema de ensino; a gestão das relações de poder e de eventuais conflitos que perpassam o quotidiano escolar, envolvendo pessoal docente, discente, técnico-administrativo ou da comunidade; as demandas específicas de formação ou de interação com a comunidade/meio social onde a escola se encontra (uso do espaço físico, participação e promoção de eventos culturais etc.); promoção da transparência nas ações administrativas e de gestão, de modo a proporcionar melhores condições de desenvolvimento do trabalho escolar em seu todo. (p. 3) 
Levando-se em consideração as reflexões conduzidas por Lück (2013) e Souza (2010), podemos considerar que há uma gama muito grande de atribuições relacionados à essa dimensão da gestão. Dentre as principais atribuições da gestão administrativas citamos abaixo algumas que consideramos essenciais.

a) Planejamento das ações e rotina administrativa

A despeito das dificuldades para por em prática os processos de planejamento, a ação de planejar, segundo Lück (2009) é importante porque "contribui para a coerência e consistência das ações, promovendo a superação do caráter aleatório, ativista e assistemático" (p. 33). O planejamento deve anteceder às ações, de maneira que permita ao diretor conhecer o funcionamento da escola, suas necessidades e demandas. $O$ processo de planejamento pode ocorrer em conjunto com a comunidade escolar, indicar os objetivos e os meios para sua execução, evitando assim a situação de improvisação.

É essencial que o planejamento seja participativo, podendo ser feito mensal, semestral ou anualmente, com o intuito de mostrar evidências, fatos, situações e ações a serem executadas (Santana; Gomes; Barbosa, 2012). Para esses autores, do mesmo modo que existem dificuldades em relação ao planejamento, ocorre o mesmo em relação à avaliação. Ainda existe muita resistência quanto à aplicação desse mecanismo de gestão em razão de perdurar uma cultura de avaliação punitiva tanto a nível institucional como individual. Em geral, há receios quanto à avaliação e exposição dos resultados dos trabalhos realizados. No entanto, é pela avaliação que se evidencia as dificuldades que ocorreram na prática diária, mediante a confrontação entre o planejamento e o funcionamento real do trabalho (Libâneo, Oliveira e Toschi, 2012).

O funcionamento da escola, bem como a qualidade da aprendizagem dos alunos, depende de um bom planejamento, boa direção e de formas democráticas e eficazes de gestão do trabalho escolar. Uma escola bem organizada depende da atitude e postura do diretor em administrar com eficiência seus recursos materiais e financeiros bem como o trabalho de seu pessoal, propiciando as condições favoráveis às atividades de ensino e aprendizagem (Libâneo, 2003).

Nesse ponto, o conhecimento das legislações que regem a escola é essencial para não haver dúvidas quanto às suas decisões, principalmente em relação ao planejamento e avaliação das ações. O regimento escolar é um documento que aponta as atribuições inerentes a todos os servidores da escola e, portanto, é importante o diretor conhecer o que determina esse documento porque envolve o funcionamento da escola como um todo.

Segundo Bortolini (2013), no bom desempenho da rotina administrativa é papel do diretor: refletir sobre o funcionamento da secretaria; como acontece a relação entre a secretaria e os demais setores da escola; dar suporte para o profissional da secretaria atuar na construção e implementação do projeto político-pedagógico; conhecer a função social da secretaria escolar; promover a relação entre a secretaria e os demais setores da escola; analisar a LDB em seus principais artigos; atuar na organização de arquivos e documentos da secretaria escolar, para assegurar a qualquer tempo a vida funcional do aluno; conhecer a estrutura e o funcionamento da unidade escolar, como resoluções, matrizes curriculares, atos legais, regimento, conhecer a legislação no que tange o correto 
preenchimento do livro de registro de classe; conhecer o regimento escolar e a resolução que ampara o calendário escolar.

Os fatores citados são essenciais para dar suporte ao diretor, com vistas a coordenar as ações da escola com maior segurança.

b) Espaço físico, materiais didáticos e recursos financeiros

Toda escola necessita de espaço físico condizente com a realidade atual, ou seja, o correto seria possuir espaços para salas de aula, laboratórios, biblioteca, coordenação, direção, espaço de lazer além dos equipamentos, mobiliários e materiais que serão importantes para o êxito do trabalho escolar. Entretanto, apesar de empenho do diretor em conseguir que a escola obtenha o máximo de equipamentos, bem como um espaço físico que seja favorável a todos, nem sempre tem como obter esse controle uma vez que, algumas decisões ficam a cargo dos órgãos superiores.

Quanto aos recursos tecnológicos ou laboratório de informática, algumas escolas até possuem laboratório, porém, os equipamentos estão encaixotados e não dispõem de pessoal que os opere. Às vezes nem mesmo o diretor possui o domínio mínimo para uso dos equipamentos. Além disso, outro fator importante é o material didático-pedagógico para a melhoria da qualidade do ensino. No que se refere aos recursos financeiros, percebe-se que cada vez mais o diretor necessita de conhecimentos básico sobre o assunto.

Nesse contexto, Cury (2007) reforça a ideia de que todo diretor terá que lidar com recursos financeiros no âmbito da escola. Portanto, é uma dimensão que não pode ser ignorada e os gestores devem conhecer elementos básicos da dinâmica dos recursos recebidos, "não só para ser guardiães morais da destinação legal desses recursos, mas também para gerir os recursos destinados diretamente à escola e com isso poder auxiliar o órgão executivo na indicação das necessidades materiais da escola" (p. 490).

Se a escola administra com eficiência seus recursos materiais e financeiros, o trabalho de seu pessoal e os procedimentos de gestão voltados para a eficácia do processo ensino aprendizagem, a escola então pode ser considerada uma escola bem organizada (Libâneo; Oliveira; Toschi, 2012).

c) Gestão de pessoas

Esta dimensão diz respeito às pessoas que participam do trabalho da escola, a exemplo dos professores, técnicos administrativos, pessoal de apoio, vice-diretores e coordenadores pedagógicos. O diretor ao lidar com recursos humanos terá o grande desafio de "desenvolver o potencial de cada pessoa para se obter maior comprometimento com resultados desejados, criando condições favoráveis no ambiente escolar" (Campos; Godoy, 2013, p. 2.371). É importante haver um clima de bom relacionamento entre as pessoas, nesse caso o gestor tem um papel muito importante, considerando que suas ações poderão demandar sucesso ou fracasso nas relações interpessoais, uma vez que é um articulador do processo educativo e incentivador do trabalho coletivo (Campos; Godoy, 2013).

Ao responder pela gestão dos recursos humanos, é importante conhecer as atribuições de cada servidor que está sob sua coordenação, conferir as tarefas que lhes são determinados, bem como resolver problemas de licenças, substituição de professor 
ou servidor, as faltas, afastamento e encaminhamento de medidas disciplinares quando necessário, ou seja, por lidar com servidores, cabe ao mesmo conhecer a legislação relativa à gestão de pessoal e particularmente à que trata dos servidores de educação pública. No entanto, nem sempre o diretor dispõe desses conhecimentos, além disso, trabalha com um número mínimo de colaboradores, sendo necessário que o gestor realize trabalhos que poderiam ser exercidos por outras pessoas e otimizar seu tempo em ações de maior visibilidade para a escola.

De outra parte, Fritzen (1987) observa que "as relações interpessoais constituem a medula da vida. Elas formam e entretêm a nossa identidade pessoal. Em certo sentido, nós nos tornamos e ficamos aquilo que somos graças à atenção que nos é dispensada pelos outros" (p. 73). Considerando o ponto de vista do autor, é essencial que diretor promova meios de interação e o bom relacionamento entre a comunidade escolar tendo como foco principal os objetivos da escola.

\section{As atribuições administrativas para as escolas municipais de Jacobina/BA}

Em Jacobina/BA as informações institucionais para o cargo de diretor constam em dois documentos: o Plano de Cargos, Carreira e Remuneração dos Profissionais de Educação Básica do Município de Jacobina (2013) e o Regimento Interno da Escola (2016). Esses documentos definem quais são as responsabilidades do diretor das escolas municipais.

O referido documento elenca as atribuições institucionais e administrativas que competem ao diretor das escolas municipais, quais sejam:

i. Solicitar material necessário à manutenção da unidade escolar ao setor responsável;

ii. Solicitar reparos e manutenção de equipamentos;

iii. Solicitar Servidor necessário ao bom andamento da escola;

iv. Determinar o setor de trabalho do servidor;

v. Envolver-se no processo de reuniões de conselho de classe, pedagógicas e de pais e mestres;

vi. Assumir função do secretário escolar em escolas de pequeno porte;

vii. Assumir a atribuição de vice-diretor nas escolas e/ou turnos que não os possuam, em atribuições que não foram dadas ao Secretário Escolar.

Já o Regimento Unificado da Escola é o documento mais recente que apresenta informações sobre o cargo de direção, que foi pensado e elaborado para atender a todas as escolas municipais. O referido documento passou em 2016 por uma reformulação em relação ao anterior, aprovado em 2004.

Determina, no art. 52, que "a direção é o órgão executivo responsável pela gestão da unidade escolar, competindo-lhe atividades de caráter técnico-pedagógico, administrativo-financeiro, patrimonial, bem como de articulação com a família, com a comunidade escolar e entorno da escola e com os poderes públicos locais." Consta que: o cargo de diretor, considerando as exceções previstas na legislação em vigor, serão ocupados por servidor, ocupante de cargo da carreira de professor ou de coordenador pedagógico do magistério público municipal, com formação em licenciatura, eleito democraticamente pela comunidade escolar e ou designado pelo secretário de Educação do Município. 
Nesse documento, consta das seguintes atribuições de gestão: atribuições de caráter pedagógico, administrativo, financeiro e de articulação com a família e a comunidade.

Assim, as atribuições administrativas, segundo regimento escolar são:

i. coordenar as atividades administrativas da unidade escolar;

ii. subsidiar os profissionais da unidade escolar, no tocante às normas vigentes e apresentar aos órgãos superiores da administração situações que estejam em desacordo com a legislação, buscando soluções imediatas;

iii. legalizar, regularizar e dar autenticidade à vida escolar dos estudantes;

iv. cumprir e fazer cumprir as disposições contidas nos atos administrativos gerais e na programação escolar

v. assinar atos e portarias disciplinadores da administração e funcionamento da unidade escolar;

vi. examinar e aprovar, com os demais órgãos, relatórios apresentados pelos órgãos da unidade escolar;

vii. supervisionar a distribuição da carga horária obrigatória dos servidores da unidade escolar, registrando faltas de professores e enviando o registro mensalmente para o órgão central;

viii. garantir a reposição de aulas decorrentes das faltas dos professores, registrando, também nestes casos, as respectivas faltas;

ix. convocar os professores para a definição da distribuição, mantendo atualizadas as informações das aulas de acordo com a sua habilitação, adequando-as à necessidade da unidade escolar e do professor

$x$. controlar a frequência dos servidores da unidade escolar;

xi. elaborar anualmente e controlar a escala de férias dos servidores;

xii. responder pelo cadastramento e registros relacionados com a administração de pessoal funcionais dos servidores na unidade escolar;

xiii. comunicar à Secretaria Municipal de Educação do município a necessidade de professores ou existência de excedentes por área e disciplina;

xiv. realizar os procedimentos administrativos pertinentes, de acordo com a legislação em vigor e no disposto neste Regimento, para apuração de faltas disciplinares dos professores, servidores administrativos e estudantes da unidade escolar garantindo o direito de ampla defesa;

XV. coordenar as atividades financeiras da unidade escolar, na forma da legislação;

xvi. elaborar e submeter à aprovação de dois terços dos componentes do Conselho Escolar o plano de aplicação dos recursos oriundos de qualquer fonte quer em regime de repasse, quer de desconcentração ou descentralização;

xvii. programar, registrar, executar e acompanhar as despesas da unidade escolar; xviii. ao final do exercício financeiro, apurar o saldo existente em cada conta e elaborar o processo de prestação de contas anual;

xix. publicar, anualmente, os valores dos recursos financeiros recebidos pela unidade escolar, com os respectivos gastos e saldos;

xx. articular e integrar a unidade escolar com a família e a comunidade;

xxi. divulgar na comunidade os resultados e outras informações da unidade escolar; 
xxii. notificar ao Conselho Tutelar do Município a relação dos estudantes que apresentem quantidade de faltas acima de $50 \%$ (cinquenta por cento) do percentual máximo de $25 \%$ (vinte e cinco por cento) das aulas previstas e dadas.

Analisando as atribuições elencadas no regimento interno percebemos que o diretor fica com uma demanda muito grande de atividades a serem desenvolvidas ou acompanhadas por ele, demonstrando uma centralidade de ações.

Vale ressaltar que, ao longo de outros capítulos do regimento escolar, aparecem outras ações que o diretor deverá cumprir, além das constantes acima. Percebemos um diferencial nas atribuições que constam no regimento interno e no plano de cargos. No regimento há uma quantidade muito maior de atribuições direcionadas ao diretor, inclusive a gestão dos recursos financeiros. No plano de cargos essa questão não está explícita como no regimento das escolas.

Mesmo havendo uma divisão das atribuições entre o diretor, o vice-diretor e o coordenador pedagógico, o que se imagina é que, em alguns casos, as ações terminam ficando, de fato, sob a responsabilidade do diretor. Pode haver ainda uma sobrecarga de atividades, caso seja necessário assumir a função de vice-diretor ou secretário da escola, no caso da inexistência desse profissional.

Diante das atribuições elencadas e que constam das normas institucionais, percebese que o diretor das escolas de Jacobina/BA têm em suas atribuições um poder maior e centralizador determinado no regimento escolar. Entretanto, todo esse poder também demanda maior responsabilidade e tempo direcionado ao trabalho na escola. Fica evidente nas legislações que as decisões na escola ficam a cargo do diretor e, por isso, há a necessidade de uma equipe gestora que possa dar um suporte efetivo nas decisões da escola para haver uma gestão realmente compartilhada.

\section{Metodologia}

Nossa pesquisa sobre a percepção dos diretores acerca da gestão das escolas municipais de Jacobina/BA, utilizamos como metodologia o estudo de caso. Envolveu um universo de 22 diretores que atuam do primeiro ao nono ano do ensino fundamental. Inicialmente, realizamos um levantamento de pesquisa bibliográfica e documental. Quanto à coleta de dados optamos pela aplicação de questionário. O presente estudo fez uso de variáveis predominantes ordinais, decorrentes de aplicação de escala tipo Likert. O objetivo da pesquisa destinou-se analisar como os diretores percebem as atribuições administrativas que lhes são demandadas para desenvolver a gestão das escolas municipais de Jacobina/BA.

A organização das proposições levou em conta a escala ordinal tipo Likert com 5 pontos (Vieira, 2009), tratada estatisticamente como métrica de observação intervalar: (1) Discordo totalmente (DT); (2) Discordo parcialmente (DP); (3) Indeciso (I); (4) Concordo parcialmente (CP); (5) Concordo totalmente (CT). Por serem oriundos de uma escala Likert, os dados coletados são qualitativos nominais. O questionário passou por um processo de validação, a fim de analisar e conferir confiabilidade.

$\mathrm{Na}$ análise, os dados foram exportados para os softwares estatísticos SPSS, que tratou das questões do perfil dos respondentes, e Modalisa, que fez o tratamento das questões da escala Likert. Para facilitar a análise estatística da base de dados, a tabulação recebeu caracteres numéricos; respostas deixadas em branco foram 
reconhecidas automaticamente pelo SPSS e pelo Modalisa como dados ausentes. A apresentação dos dados foi realizada por grau de concordância (GC) e foram analisados e interpretados, a fim de responder aos objetivos da pesquisa.

\section{Percepção dos diretores acerca das atribuições na dimensão administrativa: análise e resultados}

Após a compilação das proposições relacionadas às atribuições na dimensão administrativa, elaboramos o quadro 1, que apresenta o resultado do grau de concordância (GC), referente às questões respondidas no questionário. Buscamos, pela análise dos dados, verificar o percentual de impacto de cada questão, segundo a percepção dos diretores das escolas municipais de Jacobina/BA elencados para a pesquisa. A utilização da técnica de grau de concordância (GC) permitiu analisar percentualmente a incidência de cada concordância e discordância relacionadas às alternativas/respostas apresentadas pelos diretores.

Foi utilizado o grau de concordância segundo a proposta de Macnaughton (1966), Wilder Jr. (1981), complementado pela tabela de concordância de Davis (1976).

Quadro 1 -

Resultado de grau de concordância/discordância relacionada a cada tópico elencado, segundo Macnaughton (1986) e Wilder Jr. (1981).

\begin{tabular}{|c|c|c|c|}
\hline \multicolumn{4}{|c|}{ Planejamento das ações da escola } \\
\hline $\begin{array}{c}\text { Grau de } \\
\text { concordância }\end{array}$ & Proposição & Dimensão/atribuição & Status \\
\hline 13,6 & $\begin{array}{l}\text { 1. A elaboração do planejamento } \\
\text { da escola - plano escolar - fica } \\
\text { exclusivamente sob a a } \\
\text { responsabilidade do diretor. }\end{array}$ & Administrativa/planejamento & Discordante \\
\hline 90,9 & $\begin{array}{l}\text { 2. A elaboração do planejamento } \\
\text { da escola - plano escolar - } \\
\text { acontece com a participação de } \\
\text { alguns segmentos da escola. }\end{array}$ & Administrativa/planejamento & Concordante \\
\hline \multicolumn{4}{|c|}{ Gestão de pessoas } \\
\hline $\begin{array}{c}\text { Grau de } \\
\text { concordância }\end{array}$ & Proposição & Dimensão/atribuição & Status \\
\hline 68,2 & $\begin{array}{l}\text { Os diretores encontram } \\
\text { dificuldades em acompanhar e } \\
\text { avaliar as atividades } \\
\text { desenvolvidas pelos servidores } \\
\text { da escola. }\end{array}$ & $\begin{array}{c}\text { Administrativa/gestão de } \\
\text { pessoas }\end{array}$ & Concordante \\
\hline 86,4 & $\begin{array}{l}\text { Existe carência de servidores } \\
\text { para auxiliar a realização das } \\
\text { atividades administrativas, } \\
\text { sobrecarregando o diretor com: } \\
\text { distribuição de classe, } \\
\text { acompanhamento de caderneta, }\end{array}$ & $\begin{array}{c}\text { Administrativa/gestão de } \\
\text { pessoas }\end{array}$ & Concordante \\
\hline
\end{tabular}




\begin{tabular}{|c|c|c|c|}
\hline & elaboração de ofícios etc. & & \\
\hline 81,8 & $\begin{array}{l}\text { O vice-diretor é atuante, } \\
\text { facilitando a divisão de tarefas e } \\
\text { responsabilidades. }\end{array}$ & $\begin{array}{c}\text { Administrativa/gestão de } \\
\text { pessoas }\end{array}$ & Concordante \\
\hline 95,5 & $\begin{array}{l}\text { As escolas dispõem de } \\
\text { secretário escolar para auxiliar o } \\
\text { trabalho do diretor. }\end{array}$ & $\begin{array}{c}\text { Administrativa/gestão de } \\
\text { pessoas }\end{array}$ & Concordante \\
\hline 81,8 & $\begin{array}{l}\text { A escola dispõe de uma } \\
\text { coordenação pedagógica } \\
\text { efetiva, o que facilita o trabalho } \\
\text { do diretor com as questões } \\
\text { pedagógicas. }\end{array}$ & $\begin{array}{c}\text { Administrativa/gestão de } \\
\text { pessoas }\end{array}$ & Concordante \\
\hline 66,7 & $\begin{array}{l}\text { A ausência de habilidade e } \\
\text { competência de alguns } \\
\text { servidores técnico-administrativo } \\
\text { é um obstáculo para a gestão. }\end{array}$ & $\begin{array}{c}\text { Administrativa/gestão de } \\
\text { pessoas }\end{array}$ & Concordante \\
\hline \multicolumn{4}{|c|}{ Rotina administrativa } \\
\hline $\begin{array}{c}\text { Grau de } \\
\text { concordância }\end{array}$ & Proposição & Dimensão/Atribuição & Status \\
\hline 77,3 & $\begin{array}{l}\text { Existem entraves na } \\
\text { consecução de pequenas } \\
\text { reformas, por parte dos órgãos } \\
\text { superiores. }\end{array}$ & $\begin{array}{l}\text { Administrativa/rotina } \\
\text { administrativa }\end{array}$ & Concordante \\
\hline 90,9 & $\begin{array}{l}\text { A escola necessita de } \\
\text { equipamentos modernos por } \\
\text { serem imprescindíveis ao } \\
\text { desenvolvimento das atividades } \\
\text { de gestão das escolas. }\end{array}$ & $\begin{array}{c}\text { Administrativa/rotina } \\
\text { administrativa }\end{array}$ & Concordante \\
\hline 95,5 & $\begin{array}{l}\text { Existe demora de retorno quanto } \\
\text { às solicitações de suprimentos, } \\
\text { equipamentos e mobiliários. }\end{array}$ & $\begin{array}{l}\text { Administrativa/rotina } \\
\text { administrativa }\end{array}$ & Concordante \\
\hline 9,1 & $\begin{array}{l}\text { O diretor tem dificuldades em } \\
\text { prestar contas dos recursos } \\
\text { financeiros da escola. }\end{array}$ & $\begin{array}{c}\text { Administrativa/rotina } \\
\text { administrativa }\end{array}$ & Discordante \\
\hline 59,1 & $\begin{array}{l}\text { Maior parte do tempo do diretor } \\
\text { é destinado às atividades } \\
\text { administrativas. }\end{array}$ & $\begin{array}{c}\text { Administrativa/rotina } \\
\text { administrativa }\end{array}$ & Concordante \\
\hline 40,9 & $\begin{array}{l}\text { As saídas constantes para } \\
\text { participar de reuniões externas } \\
\text { geram transtornos para a } \\
\text { escola. }\end{array}$ & $\begin{array}{l}\text { Administrativa/rotina } \\
\text { administrativa }\end{array}$ & Discordante \\
\hline
\end{tabular}

Nas proposições referentes às atribuições de planejamento das ações da escola, constatamos uma concordância muito forte quando os diretores afirmam dividir a elaboração do plano escolar com alguns segmentos (GC-90,0) e outra com discordância substancial, referente à elaboração do planejamento de forma individual (GD-13,6). Observamos que existe total coerência nas respostas e este é o comportamento esperado 
na gestão da escola. Portanto, concluímos que, apesar da contradição concordante/discordante -, existe lógica nas respostas dos diretores e há indícios de que, em algumas escolas, a gestão tende a ser participativa.

No que tange à gestão de pessoas, todas as questões foram concordantes, em graus diferenciados. Verificamos uma concordância muito forte por parte dos diretores ao confirmarem que as escolas têm secretários escolares (GC-95,5); seguida de três proposições com concordância substancial, em que os diretores veem a boa atuação do vice-diretor (GC-81,8) e percebem uma coordenação pedagógica efetiva (GC-81,8). As respostas confirmam que as escolas mantêm, em seu quadro, os profissionais que auxiliam diretamente o trabalho do diretor, tanto na parte administrativa como na pedagógica. Entretanto, para alguns diretores, as escolas necessitam de mais servidores para as atividades administrativas (GC-86,4).

Detectamos duas proposições com Concordância fraca: a primeira diz respeito às dificuldades de alguns diretores em avaliar e acompanhar as atividades desenvolvidas pelos servidores (GC-68,2). Sendo essa uma das atribuições do diretor, determinada no regimento escolar, acreditamos que tal fator merece atenção especial, uma vez que mais da metade dos diretores passa por essa situação. A escola, como qualquer outra organização, precisa ter uma liderança que possa acompanhar, auxiliar e incentivar as pessoas para melhor realizar suas tarefas. Por outro lado, mesmo confirmando as dificuldades em avaliar e acompanhar o trabalho dos servidores, alguns diretores percebem que existem funcionários sem habilidades e competências para o serviço, sendo um obstáculo para a gestão (GC-66,7).

Esses resultados levam ao entendimento de que as atribuições referentes à gestão de pessoas precisam ser aprimoradas, uma vez que é responsabilidade do diretor acompanhar e avaliar o trabalho dos servidores, bem como incentivá-los a participarem de capacitação, o que deverá constar no planejamento anual da Secretaria de Educação. Manter a harmonia no ambiente de trabalho e envolver os servidores em torno de um objetivo comum demanda conhecimentos, paciência, mudança de atitudes, valores e vontade de mudança.

$\mathrm{Na}$ rotina administrativa foram elencadas duas proposições com grau de concordância muito forte. Podemos concluir que estão de acordo com o esperado, uma vez que é importante os diretores perceberem a necessidade de equipamentos modernos para o desenvolvimento das atividades de gestão (GC-90,9), bem como solicitar suprimentos, equipamentos e mobiliários aos órgãos superiores. No entanto, os diretores concordam que existem dificuldades no retorno das respostas (GC-95,5), o que pode trazer transtornos, uma vez que as escolas municipais ainda têm uma dependência administrativa e financeira significativa em relação à Secretaria de Educação. Esse resultado é um indicativo de que existem ações que não dependem somente do diretor, em função do resultado estar atrelado a outros setores do órgão municipal.

Ainda em relação à rotina administrativa, alguns diretores percebem a existência de entraves na consecução de pequenas reformas, por parte dos órgãos superiores (GC77,3 ), sendo, portanto, uma concordância moderada, indicando que esse problema não ocorre em todas as escolas. Concluímos, diante das respostas elencadas, que os diretores cumprem suas atribuições a contento. Os empecilhos vêm por parte das instâncias superiores, que deveriam auxiliar e não atrapalhar o trabalho do diretor. 
Somente alguns diretores percebem que a maior parte de seu tempo é destinada a atividades administrativas (GC-59,1), configurando como uma concordância desprezível. Portanto, alguns não veem problemas na quantidade de atribuições no setor administrativo. Imaginamos que, nessa proposição, haveria um grau de concordância maior, até porque boa parte afirma faltar pessoal, além da ausência de capacitação de alguns servidores da secretaria.

Normalmente os gestores de escolas públicas reclamam da burocracia para prestar contas dos recursos financeiros da instituição. Porém, esse parece não ser um problema para os diretores que participaram da pesquisa, uma vez que a maioria discorda de que tem dificuldades em prestar contas dos recursos financeiros (GD-09,1), sendo um grau de discordância muito forte. Esse resultado se constituiu em uma surpresa positiva porque imaginávamos que haveria um grau de concordância e não de discordância. Isso é positivo porque, diante das respostas, o problema referente à prestação de contas, pelo menos nas escolas municipais de Jacobina/BA, parece ser uma questão resolvida para a grande maioria.

Houve um grau de discordância desprezível em relação às saídas da escola para reuniões externas. Nesse caso, a maioria discorda que as saídas são um transtorno para a escola (GD-40,9), o que permite concluir que, em algumas escolas, existe uma parceria bem resolvida entre a equipe gestora - secretário, vice-diretor e coordenação pedagógica - que tem o controle na escola, apesar da ausência do diretor.

Portanto, as dimensões/atribuições, de acordo com o grau de concordância/discordância, levam a concluir que, apesar dos empecilhos, a maioria dos diretores tenta viabilizar mudanças em relação à forma de gerir a escola. Entendemos que cada resposta passou por uma análise apurada, recorrendo ao imaginário dos acontecimentos reais para ter maior veracidade, uma vez que reporta à lembrança de atividades realizadas no cotidiano escolar, passando informações relevantes sobre a gestão da escola a partir de suas atribuições.

\section{Considerações finais}

Imaginamos que somente ao assumir o cargo parte dos diretores das escolas pesquisadas passaram a conhecer quais são suas atribuições. $\mathrm{Na}$ dimensão administrativa as principais atribuições demandadas para os diretores das escolas municipais de Jacobina/Bahia, estão relacionadas às seguintes atividades: planejamento das ações da escola, gestão de pessoas, rotina administrativa - envolve gerir recursos financeiros - e promoção da participação dos diversos segmentos da unidade escolar.

Independentemente do que consta nos documentos, as mudanças na forma de gerir a escola aumentaram as demandas de atribuições para os diretores, bem como a responsabilidade e o tempo direcionado ao trabalho na escola. $\mathrm{Na}$ dimensão administrativa concluímos que parte dos diretores ficaram em dúvida se as demandas dessa dimensão sobrecarregam seu tempo na escola. No entanto, terminam concordando que dão mais atenção à parte administrativa em relação às demais atribuições. Deduzimos que esse resultado pode ser justificado em função da quantidade de ações que são demandadas na parte administrativa. 
Foi possível observar, também, os principais avanços e dificuldades que incidem sobre 0 trabalho dos diretores no cotidiano escolar em relação às atribuições administrativas. Embora a pesquisa envolva apenas um município específico, Jacobina/BA, considerada uma cidade de médio porte, com legislações próprias para gerir suas escolas, compreendemos que os temas aqui abordados poderão contribuir de modo mais amplo para os estudos sobre a gestão escolar no interior baiano.

Sobre a gestão de pessoas acreditamos que, por falta de conhecimento sobre relações interpessoais, os diretores encontram dificuldades no que tange ao acompanhamento do trabalho dos servidores. Entretanto, é importante que o diretor e todos os seus auxiliares participem de cursos de formação continuada, a fim de que se tornem capazes de acompanhar as transformações inerentes ao bom andamento da escola.

Apontamos como um dos entraves da gestão das escolas, que não depende somente do diretor, podendo ser um impeditivo à participação nas escolas, é a autorização via decreto para a formação dos colegiados escolares. Esta é de responsabilidade do gestor municipal, o que até o momento da conclusão deste estudo ainda não estava em vigor. Sendo o colegiado formado pela representação dos diversos segmentos da comunidade escolar, podemos imaginar que, tanto administrativa, quanto pedagogicamente, a participação pode não estar acontecendo a contento, apesar da boa vontade e das estratégias realizadas pela maioria dos diretores.

Embora a não formação do colegiado seja um fator que dificulta a participação, alguns diretores estão buscando estratégias para viabilizar o máximo de participação, dentre as quais: continuar com a composição do colegiado, mesmo sem validade legal; convocação de reuniões envolvendo todos os segmentos para as decisões ou até mesmo convocação de novos integrantes, mesmo sem o suporte do decreto, como forma de não perder a credibilidade perante a comunidade escolar.

Sobre a questão financeira os diretores se mostram mais preocupados. Acreditamos que isso esteja relacionado à responsabilidade fiscal e a represálias caso haja problemas nas prestações de contas, pois, mesmo deixando o cargo após o mandato, eles continuam respondendo pelos atos praticados durante um prazo de três anos, o que pode comprometer as finanças da escola, em razão do bloqueio dos recursos da escola para o ano seguinte.

Desse modo, concluímos que a maioria dos diretores está sobrecarregada de atividades e tem dificuldades na realização de algumas atribuições. Mesmo assim, estão tentando implantar mudanças significativas na forma de gerir as escolas. Diante do exposto, foi possível detectar alguns avanços na gestão das escolas municipais de Jacobina, segundo resposta dos diretores. Esses avanços podem estar relacionados ao número de diretores que, apesar da pouca experiência no cargo, estão trazendo modificações na forma de gerir a escola.

Por outro lado, observamos que os diretores enfrentam algumas dificuldades ou entraves ao exercerem suas atribuições de forma efetiva. A maioria dessas se deve ao não cumprimento de algumas ações que são de responsabilidade das instâncias superiores. Diante dos resultados, julgamos necessário que os diretores estejam imbuídos 
de conhecimento sobre gestão, legislação educacional e relacionamento interpessoal, tenham liderança e competência para articular de forma efetiva as ações em todas as dimensões da gestão, além da integração com os diversos segmentos da escola e da comunidade.

\section{Referências}

ASSIS, Luiz. Oliveira. Rupturas e permanências na história da educação brasileira: do regime militar à LDB/96. Disponível em http://curriculohistoria.files.wordpress.com /2009/09/clara.pdf. Acesso em 17 mar. 2014.

BORTOLINI, Jairo César. O papel do diretor na gestão democrática: desafios e possibilidades na prática da gestão escolar. Interletras, v. 3, n. 17, 2013, p. 1-15.

CAMPOS, Carmen R de; GODOY, Miriam A. B. Relações interpessoais: um desafio para o gestor escolar. SEMINÁRIO INTERNACIONAL DE REPRESENTAÇÕES SOCIAIS, SUBJETIVIDADE E EDUCAÇÃO E SEMINÁRIO INTERNACIONAL SOBRE PROFISSIONALIZAÇÃO DOCENTE, 2, 2013. Anais ... Curitiba: PUCPR, 2013.

CARNEIRO, Breno P. B; NOVAIS, Ivan Luiz. Gestão educacional descentralizada: participação e tomada de decisão. SEMINÁRIO POLÍTICAS SOCIAIS E CIDADANIA, 3, 2010. Anais ... Salvador: Universidade Católica de Salvador, 2010. Disponível em: http://www.interativadesignba.com.br/lll SPSC/arquivos/sessao5/124.pdf. Acesso em 23 mar. 2017.

CASASSUS, Juan. Tarefas da educação. Campinas: Autores Associados, 1995.

CURY, Carlos Roberto J. Gestão democrática da educação em tempos de contradição. SIMPÓSIO BRASILEIRO DE POLÍTICA E ADMINISTRAÇÃO DA EDUCAÇÃO, 23, 2007, Porto Alegre. Anais... Porto Alegre: Anpae, 2007.

DUARTE, Marisa Ribeiro Teixeira; JUNQUEIRA, Déborah Saib Silva. Gestor educacional. In: OLIVEIRA, Dalila Andrade; DUARTE, Adriana Maria Cancella; VIEIRA, Lívia Maria Fraga. Dicionário: trabalho, profissão e condição docente. Belo Horizonte: UFMG/Faculdade de Educação, 2010. Disponível em http://www.gestrado.net.br/?pg=dicionario-verbetes\&id=30. Acesso em 23 mar. 2017.

FRITZEN, Silvino José. Relações humanas interpessoais. Petrópolis: Vozes, 1987.

LIBÂNEO, José Ccarlos; OLIVEIRA João F. de; TOSCHI, Mariza Seabra. Educação escolar: políticas, estrutura e organização. São Paulo: Cortez, 2012.

LIBÂNIO, José Carlos. Organização e gestão da escola: teoria e prática. São Paulo: Heccus, 2003.

LÜCK, Heloísa et al. A escola participativa: o trabalho do gestor escolar. Rio de Janeiro: DP\&A, 2000.

LÜCK, Heloísa. Ação integrada: administração, supervisão e orientação educacional. Petrópolis: Vozes, 2013.

LÜCK, Heloísa. Dimensões da gestão escolar e suas competências. Curitiba: Positivo, 2009.

SANTANA, S. da S. Santana; GOMES, Roseli da S; BARBOSA, Joelma S. O papel do gestor na elaboração e execução do projeto político pedagógico numa visão democrática. Cadernos de Pedagogia, São Carlos, v. 6 n. 11, 2012, p. 62-73. 
MARTINS, Ana, P. Maioli; BOCANELLI, Cláudio R. O papel do diretor de escola frente aos novos desafios da gestão escolar. Colloquium Humanarum, Presidente Prudente, v. 7, n. 2, 2010, p. 80-85.

NASCIMENTO, Leandro G. M; LEAL, Ione O. Jatobá; NOVAES, Ivan L. Conselho escolar: uma análise das experiências em escolas da rede municipal de ensino de Salvador/Bahia. ENCONTRO DE PESQUISA EDUCACIONAL DO NORTE E NORDESTE, 22, 2014. Anais ... Natal: UFRN, 2014.

NOVAES, Ivan L; LOUIS, Roland. Elaboração de um instrumento de medida para uma pesquisa sobre a percepção dos diretores de escolas acerca da descentralização da gestão escolar. In: NASCIMENTO, Antonio Dias; HETKOWSKI, Tânia Maria (orgs.). Educação e contemporaneidade: pesquisas científicas e tecnológicas. Salvador: UFBA, 2009, p. 41-62.

SOUZA, Ângelo $R$ de. Diretor escolar. In: OLIVEIRA, Dalila Andrade; DUARTE, Adriana Maria Cancella; VIEIRA, Lívia Maria Fraga. Dicionário: trabalho, profissão e condição docente. Belo Horizonte: UFMG/Faculdade de Educação, 2010. Disponível em http://www.gestrado.net.br/?pg=dicionario-verbetes\&id=147. Acesso em 23 mar. 2017.

SOUZA, Antônio L. L. de. Direção escolar. In: OLIVEIRA, Dalila Andrade; DUARTE, Adriana Maria Cancella; VIEIRA, Lívia Maria Fraga. Dicionário: trabalho, profissão e condição docente. Belo Horizonte: UFMG/Faculdade de Educação, 2010. Disponível em http://www.gestrado.net.br/?pg=dicionario-verbetes\&id=135. Acesso em 23 mar. 2017.

VIEIRA, Sonia. Como elaborar questionários. São Paulo: Atlas, 2009.

WEISS, Donald. Como resolver ou evitar conflitos no trabalho. São Paulo: Nobel, 1994.

Ione Oliveira Jatobá Leal é professora na Universidade do Estado da Bahia. Doutora em Educação pela Universidade do Estado da Bahia e pesquisadora do Grupo de Pesquisa Gestão Educacional e Formação de Gestores.

Endereço: Rua J. J. Seabra, 158 - 44700-000 - Jacobina - BA - Brasil.

E-mail: ionejatoba@gmail.com.

Ivan Luiz Novaes é professor na a Universidade do Estado da Bahia. Doutor em Educação (PhD) pela Université de Sherbrooke, Canadá, e pós-doutoramento pela Universidade Federal do Rio Grande do Sul. Coordenador do Grupo de Pesquisa Gestão Educacional e Formação de Gestores.

Endereço: Rua J. J. Seabra, 158 - 44700-000 - Jacobina - BA - Brasil.

E-mail: ivanovaes@gmail.com.

Recebido em 18 de novembro de 2017.

Aceito em 7 de dezembro de 2017. 